The study of doping: how to produce intelligence from Internet forums.

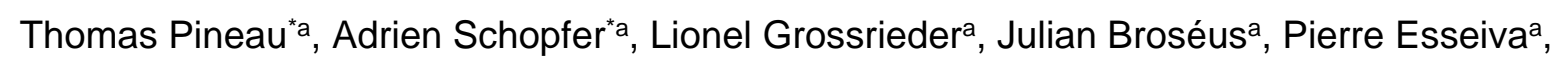

Quentin Rossya

aSchool of Criminal Justice

University of Lausanne

1015 Lausanne

Switzerland

“Corresponding authors: thomas.pineau@unil.ch \& adrien.schopfer@unil.ch

11 Abstract

12 Despite the predominant role played by Internet in the distribution of doping substances, little 13 is currently known about the online offer of doping products. Therefore, the study focuses on

14 the detection of doping substances and suppliers discussed in Internet forums. It aims at 15 having a comprehensive understanding of products and sellers to lead an operational 16 monitoring of the online doping market.

17 Thirteen community forums on the Internet were investigated and one million topics were 18 extracted with source code scrappers. Then, a semantic analysis was conducted with a 19 semi-automatic process to classify the relevant words according to doping matters. 20 Additionally, the ranking of doping products, active substances and suppliers in regards to 21 the number of contributors to the forums were established and analysed over time. Finally, 22 promotion methods of suppliers were evaluated.

23 The results show that anabolic androgenic steroids, used to enhance body image and 24 performance, are the most discussed type of products. A temporal analysis illustrates the 25 stability of the most popular products as well as the emergence of new products such as 26 peptides (e.g. CJC-1295). 327 suppliers were detected, mostly with dedicated websites or 27 direct sales by e-mail as selling methods.

28 Globally, the implemented methodology shows its ability to detect products and suppliers as 29 well as to follow their temporal trends. The intelligence will serve the definition of online 30 monitoring strategies (e.g. the selection of appropriate keywords). Additionally, it also allows 31 the adjustment of customs inspection strategies and anti-doping analysis by monitoring the 32 popular and emerging substances.

34 Keywords: illicit market, doping, scraping, intelligence-led screening, operational monitoring, 35 forums 
37 The online market of doping products occupies a crucial place in the distribution and accessibility of products $[1,2]$. The study of illicit online markets is a problem which can be described in regards to usages of the Internet to support the market. Indeed, online services may be used for several aims. They may be classified in three related processes: (1) the promotion process which uses online services to advertise and ease the accessibility to marketplaces, (2) the selling process which takes places in multiple online environments, and (3) the discussion process which aims at sharing information and reviews about products and sellers. If the selling process is central to the study of illicit online markets, promotion and discussion processes are dependent issues that are also critical to tackle the global phenomenon. Indeed, the discovery of illicit online markets requires to set up an appropriate research strategy. This article focuses on the use of information gathered during the discussion process to guide the search for online marketplaces.

Access to Internet sale spaces can take different paths, whether on the world wide web including indexed websites (surface web) and not indexed websites (deep web) or overlay networks (darknet) such as TOR.

For instance, search engines or directories can index webpages. Forums, social networking services, sharing websites or spam may also be used to broadcast hyperlinks to webpages or directly promote products [3,4]. Thus, the research of these promotion means requires the identification of third-party services and information-sharing websites as well as the definition of relevant keywords to perform target researches. Indeed, doing queries on different data sources, whether they are search engines or the content of a website (e.g. social networking services) is based on the use of keywords related to the problem to detect. Therefore, a set of appropriate keywords according to the targeting content should be chosen to maximise the efficiency of the process. This raises the question of keywords selection. These keywords can be defined based on those used by already known sale websites (e.g. the keywords tag in the source code or the textual content from the webpage). This strategy is limited because it assumes that a sample of websites is already known and it is solely focused on indexed websites. Moreover, the keywords obtained are not necessarily suitable for other online communication spaces and unknown marketplaces. Other sources of information should thus be used to guide the selection of keywords. The chosen approach in this research stems from the study of online information sharing spaces, in particular on community forums on the surface web, excluding deep web and darknet forums. The assumption is that the most discussed terms found on community forums are the most suited to search websites or sale announcements. Deep web and darknet forums were not taking into account in this study.

71 Indeed, doping is not considered as a very priority issue by law enforcements and can be

72 freely discussed on the surface web unlike pedophilia for example. 
The described approach is comparable to the process named "Intelligence-led crime scene processing" formalised by Ribaux et al. $[5,6]$. This process aims at guiding the collection of forensic traces on a crime scene in the light of the knowledge previously accumulated about criminal activities. In particular, this knowledge is produced from the intelligence process which aims to detect and follow the evolution of crime problems [7]. The process is decomposed according to the following steps: (1) data collection; (2) integration in a structured memory; (3) detection of specific problems (through pattern recognition); (4) analysis of the detected problems; (5) intelligence production to guide the decision-making; and (6) impact assessment of the actions taken. The Figure 1, adapted from Ribaux [7], express the steps of the intelligence process in the case of illicit markets on the Internet.



Figure 1 - Operational monitoring process in the case of illicit markets on the Internet.

The arrow "intelligence-led screening", on the Figure 1, describes the research process of selling spaces on the Internet. This process is guided by the knowledge acquired during the data analysis of the crime problem. In this case, the analysis of community forums is used as a source of knowledge to identify and select the keywords needed to detect the selling spaces of doping products.

92 Forums analysis involves setting up a process that can be described by the previous 93 approach. Thus, these discussion spaces are integrated in the global monitoring process of 94 illicit markets on the Internet. The acquisition phase (1) includes a research of forums 95 containing discussions about doping products, followed by an acquisition of their content. 96 The acquired raw data includes general information about posts, members as well as the 
promotional content (i.e. advertising, hyperlinks). The integration phase (2) aims at structuring the relevant information by a semantic analysis of the topics to extract information on products, active substances and suppliers. The detection phase (3) is mainly on the identification of the most discussed terms and the identification of suppliers and their contact means. The analysis step (4) focuses on the temporal analysis of detected products and sellers in order to evaluate their trends and follow their evolution. Additionally, activity patterns linked to selling contact means such as dedicated websites or e-mail are analysed.

104 Finally, (5) the intelligence inferred on selling and consumption practices aims at guiding decision-making. In particular, to define relevant keywords to search the Internet for illicit online marketplaces. Moreover, it allows the adjustment of custom inspections strategies and anti-doping analysis by monitoring the popular and emerging substances.

\section{Previous studies}

110 A few studies have already examined the market of doping products on the Internet. Krug et 111 al. [8] have described the products that can be found on the market in Germany. The products were seized by customs between 2010 and 2013. Steroids were the major kind of 113 seizures with $87.5 \%$ of the total number. In this category, esters of testosterone, 114 mehtandienone, boldenone and trenbolone were the main substances. Donati [1] pointed 115 that the world trafficking of doping products, in particular anabolic agents, is sharply 116 increasing through the Internet. In 2000, a first study was conducted to highlight the easiness 117 to buy doping products online [9]. However, the search strategy wasn't clearly described. 118 Additionally, Cordaro et al. [10], who did not provide information on their strategy of keywords 119 selection to detect websites, have investigated 30 marketplaces selling anabolic agents to evaluate their availability on the Internet. They concluded that an average of 52 products were available with esters of nandrolone, methandrostenolone and of testosterone in the

122 highest proportion. Clement et al. [11] studied the diffusion of nonprescription steroids on the 123 Internet. They selected 5 keywords related to the brand names of steroid products. They 124 classified 100 hyperlinks found with Google in 2006 to show the proportion of pro-use 125 websites according to keywords. Like Cordaro et al. [10] the strategy to select the keywords 126 is not described. Another study done by Brennan et al. [12] used Google to search selling 127 websites using generic keywords (like "steroids", "bodybuilding" and "growth hormone"). 128 Unfortunately, there is a lack of details in the provided results (no classification of webpages, 129 no information about product available and no evaluation of keywords relevance). Moreover, 130 as the two previous studies, the authors did not mention the reasons for the keywords 131 choice.

132 Kraska et al. [13] did a sociological study of dealers in black markets. They analysed data 133 collected from several regional dealers who operated in fitness gyms. They described an 
134 interesting mechanism where a dealer began first to buy steroid products from another

135 dealer then ordered on the Internet for his personal use to finally homebrewed, with raw

136 materials, his proper products and sell them. By spending 1,500\$ in raw material, the street

137 value of his products was around $50,000 \$$. This study suggests that dealing doping products

138 is highly profitable with a low risk compared to traditional illicit drugs such as heroin and 139 cocaine.

140 Moreover, according to Kraska et al. [13], Internet forums are one of the best sources to find 141 most of the information to produce or buy doping products, especially those used for 142 enhanced body image. These kind of forums called "Gray Web forum" by Wang et al. [14] 143 are used to encourage some deviant behaviour. As demonstrated by Seale et al. [15] and 144 Barrat [16], Internet forums are a valuable qualitative source of information. They are a "safe" 145 space where individuals can share and find information namelessly, in particular about their 146 own consumption of products. Therefore, researchers can find useful information related to a 147 sensitive topic such as illegal or immoral behaviour. Additionally, forums contain information, 148 which decrease the social desirability bias that often append with surveys. Forums provide 149 non-costly, unalterable data but also a broad temporality. On the other hand, this source 150 lacks of contextual information. Thus, the attributes of the population, such as gender, age or 151 situation, are difficult to evaluate. Community forums contain rich information that can be 152 collected for analytical purpose. The obvious limitation is how to process this large amount of 153 data. Manually, it would be extremely long to extract and process all the information. 154 Therefore, as proposed by Zhou et al. [17], an automatic tool must be built to manage this 155 task.

\section{Research objectives}

158 This research aims at analysing the discussions on online forums to identify doping products 159 and online sellers, as well as to evaluate their popularity and their temporal trends regarding 160 the number of users discussing them. In particular, the approach aims at detecting the most 161 discussed products and the emerging ones, which can be used as relevant keywords to 162 search the Internet for doping marketplaces.

163 Additionally, assessing the popularity of doping products could bring some insights about 164 their consumption, based on the hypothesis that the most discussed products are the most 165 consumed. Evaluating the popularity of doping products discussed online may also be useful 166 to settle or guide public health policy and prevention strategies.

167 Finally, the study also aims at developing a general methodology to extract and process 168 large amount of data available on forums. It is assumed that the approach may be reused for 169 the investigation of other problems and on other kinds of forums and topics. 


\section{Methodology}

171 The global process is summarized in the Figure 2, and each step of the process is described

172 in the following sections. The first task is to detect online forums that contains discussions

173 about the relevant topic (in our case doping products). This may be done with a search

174 engine and by manually browsing the forums to identify their content. A general description

175 of their characteristics can then be performed (e.g. identifying their topics, number of users,

176 advertising and sponsors, etc.). Once forums are identified, it is then necessary to define

177 what information should be searched and collected. There are mainly two options: (1) to

178 browse all messages of the forum or (2) to browse the listings of topics for each subsection

179 of the forum. This choice should be guided by the research objectives. In our case, it was

180 assumed that listings of topics should be sufficient to identify products and sellers and to

181 evaluate their popularity. Indeed, one may assume that the first author of a topic would in

182 most cases indicate product and/or seller identification information in the title of his message.

183 Then a collection process has to be settled to browse all pages and crawl their content. The

184 downloaded listings are then parsed to integrate the information in a structured database

185 containing each relevant variable of listings such as titles, first author pseudonyms, dates,

186 etc. A semantic analysis of each word present in the title of the messages is then performed.

187 The process is structured in two steps: (1) an automatic filtering based on a stop-words list to

188 exclude words such as determinants, very common verbs or lexical words, numbers, etc. (2)

189 a systematic manual analysis of the reaming words to identify and classify them in categories

190 such as products, active substances, sellers, etc. Finally, a relevant indicator of popularity 191 should be chosen among the available indicators (i.e. the number of first authors, of topics, of 192 views or replies). This particular aspect is discussed in detail below.



Figure 2 - Global methodology to analyse community forums. 
Detection and selection of the forums

196 To define our sample of Internet forums, a user-oriented approach was used. Keywords were

197 submitted in three search engines; google.com, bing.com and yahoo.com. The keywords

198 used were steroid forum, growth hormone forum, peptide forum, fitness forum, aas forum,

199 doping forum, anabolic forum and their translation in French. The keywords are generic

200 terms. They are only used to construct a sample of forums for this study. As stated in the

201 introduction, the process to discover new forums can be improved using the knowledge

202 acquired during the study.

203 The first fifty outputs were manually checked for each search engine. Only French and

204 English forums were chosen. This simple approach was used based on the hypothesis that it

205 may well correspond to the typical maximal research process undertaken by a

206 French/English-speaking person interested to find forums about steroids. The research was

207 performed in February 2015, and 27 forums were detected. The forums were classified

208 according to the presence of selling or doping products sections. Eight forums were excluded

209 because no sections on doping products were available. Indeed, the excluded forums are

210 mainly about dietary supplements, medical advice or training discussions. Additionally, 2

211 forums (muscegurus.com and forums.t-nation.com) were excluded due to their architecture

212 which was very difficult to monitor automatically. The remaining forums were filtered

213 according to the number of posts (arbitrary threshold set to more than 1000) and the number

214 of members (more than 500 ). At the end, 13 forums were kept for further analysis. 


\section{Description of the forums}

216 The number of members and topics, the number of first-topic authors, the presence of

217 specific seller sections or advertising banners in the forum and the existence of a dedicated

218 sale website were extracted and reported manually (see Table 1).

219

\begin{tabular}{lcccccc}
\hline Forums & Lang. & $\begin{array}{c}\text { Number of } \\
\text { first authors }\end{array}$ & $\begin{array}{c}\text { Number of } \\
\text { members }\end{array}$ & $\begin{array}{c}\text { Number } \\
\text { of topics }\end{array}$ & $\begin{array}{c}\text { Number of } \\
\text { adverts }\end{array}$ & $\begin{array}{c}\text { Date of the first } \\
\text { topic extracted } \\
\text { (mm.yyyy) }\end{array}$ \\
\hline steroid.com & & & & & & 08.2001 \\
elitefitness.com & EN & 59028 & 308919 & 324985 & 8 & 03.2000 \\
steroidology.com & EN & 39480 & 435373 & 276079 & 3 & 01.2003 \\
ironmagazineforums.com & EN & 29149 & 312894 & 128740 & 5 & 01.2001 \\
thinksteroids.com & EN & 10776 & 113338 & 56406 & 44 & 12.2003 \\
isteroids.com & EN & 10220 & 43487 & 46022 & 6 & 10.2002 \\
eroids.com & EN & 8818 & 132980 & 34348 & 3 & 05.2011 \\
evolutionary.org & EN & 6568 & - & 25362 & 0 & 10.2009 \\
anabolicsteroidforums.com & EN & 3791 & 100818 & 21765 & 0 & 06.2012 \\
steroid-forums.com & EN & 3103 & 15385 & 23397 & 44 & 01.2011 \\
ugbodybuilding.com & EN & 2486 & 11612 & 11836 & 48 & 09.2011 \\
fr.thinksteroids.com & EN & 1125 & 5641 & 4874 & 3 & 09.2012 \\
all-steroids.com & FR & 1022 & 7069 & 2801 & 7 & 09.2011 \\
\hline Total & EN & 580 & 4895 & 1878 & 12 & - \\
\hline
\end{tabular}

220 Table 1 - Selected forums with the number of members and topics, the number of selling adverts and sale websites affiliated to the forum.

222

223

224

225

226

227

228

229

230 The sections dedicated to the products are more often than not subdivided by the type of

231 products such as steroids, growth hormones, peptides and supplements.

Forums are more often than not subdivided in subsections that may globally be classified as:

- information about products and/or sellers (brand name, advises, efficacy, prices, delivery, scam, etc.)

232 
234 Each subsection contains a list of topics linking to a dedicated page containing the first 235 message sent and the replies. The first step in the process was to define a batch of URLs by 236 subsection for each forum. The main URL of each section was extracted. Then, a batch of 237 URLs specific to each section was automatically generated according to the number of 238 pages of the section. All the URLs were then stored in a text file used to feed an automatic 239 script performing the crawling to obtain the source code of webpages.

240 A dedicated extraction process was then developed to analyse all the sections containing the 241 lists of discussions (see Figure 3). The title of each thread, the first author, the date of the 242 first post, the last author, the date of the last post, the number of replies and the number of 243 views were extracted for each discussion in each forum section.

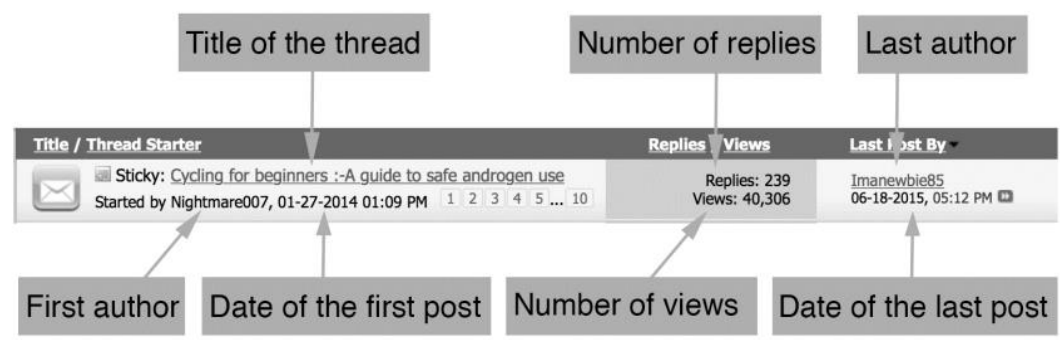

Figure 3 - Description of the extracted content.

248 A specific parser was developed to acquire the different targets embedded in the source 249 code. The identification of a stable structure and specific blocks for each forum led to the 250 development of only one extractor by forum. This step was performed using a scrapping tool: 251 import.io. This service enables to visually select the targeted structured content and find the 252 XPath of a specific content quickly. The dedicated extractors were run with a Python script 253 with all the batches of URLs. Finally, the extracted content was stored in csv files. At the end 254 of the acquisition step, 958'493 topics were extracted from the 13 Internet forums over 15 255 years.

256 The data were collected and processed in accordance with the Swiss Federal Act on Data 257 Protection (FADP). Indeed, the sources of data are publicly accessible online (without any 258 step of registration or any kind of protection) and do not contain sensitive personal data. 259 Additionally, the purpose of the study is not to identify specific peoples (i.e. virtual identities) 260 and only aims academic research purposes. 
Semantic analysis of the detected words

262 Words contained in each topic title were separated from each other with a Python script

263 using a regular expression and stored in a csv file for each forum. Then, the occurrence of

264 each word was determined in all the topics previously extracted with no case sensitivity. The

265 words with an occurrence smaller than five were excluded. To refine the list of words,

266 irrelevant words were automatically eliminated using a stop-words dictionary (in French and

267 English) provided by the Neuchâtel University ${ }^{1}[18]$. The remaining words were manually

268 examined to determine if they were related to a product or a supplier as part of doping

269 matters. The words identified as relevant were stored in a csv file referred as the "reference

270 file". During this process, all words were described with the following metadata: name, class,

271 category, active substance, group and contact information (see Tables 2 and 3).

272

\begin{tabular}{ll}
\hline Metadata & Description \\
\hline Name & Full name related to the detected word (e.g. words: "sust" name: "sustanon") \\
Class & Word reference: product or supplier \\
Category & Type of product (e.g. steroid, growth hormone, EPO, etc.) \\
Group & Group of categories adapted from the WADA prohibited list (2015) \\
Active substance & Active substance present in the product \\
Contact information & Contact information (e-mail, websites, private message) for suppliers \\
\hline
\end{tabular}

Table 2 - Description of the reference file metadata describing the detected words in all titles of the topics.

\begin{tabular}{ccccccc}
\hline Word & Name & Class & Category & Group & $\begin{array}{c}\text { Active } \\
\text { substance }\end{array}$ & Contact \\
\hline sus & sustanon & product & steroid & Steroid & testosterone & - \\
sus250 & sustanon & product & steroid & Steroid & testosterone & - \\
susta & sustanon & product & steroid & Steroid & testosterone & - \\
sustanon & sustanon & product & steroid & Steroid & testosterone & - \\
rui & RUI-Products & supplier & peptide & Peptide, GF & and EPO & http://www.rui- \\
& & & & peptide, GF & products.com/ \\
rui-products & RUI-Products & supplier & peptide & and EPO & http:/www.rui- \\
& & & & & products.com/
\end{tabular}

Table 3 - Example of the reference file describing the detected words in all titles of the topics.

278 At the end of the process, 1757 words related to doping were identified. The semantic 279 analysis of these words allows their classification as 1167 different names wherein 158 
280 active substances, 320 product brand names and 327 supplier names appeared. For each

281 supplier, a search in the posts was conducted to detect their contact information (e-mail and

282 dedicated websites).

283

284 Choice of the indicator of popularity

285 Several indicators of popularity for detected words detected may be chosen: the number of 286 topic views and responses, the number of topics containing a specific word, and the number 287 of distinct authors for each word. A Pearson correlation was calculated between the 288 indicators to assess if they measure the same popularity. All were positively correlated and 289 for 12 forums the correlations were higher than 0.641 . The lower correlations were for French 290 forums where the total number of topics and forum members are smaller. This quantitative 291 observation tends to support the hypothesis that all indicators may be used to analyse the 292 popularity and temporal trends. However, qualitative aspects should also be taken under 293 consideration. In regards to the number of views, no information is available about the 294 counting process carried out by the forum and it could be different for one to another. 295 Regarding the number of responses, some topics are very popular such as tutorial and sticky 296 topics. On the other hand, seller locked topics (only accessible by suppliers) have a very low 297 number of responses. The number of topics is highly correlated with the number of distinct 298 first authors for each forum (from 0.986 to 0.999). Finally, the number of distinct first-authors 299 avoids the overestimation of the popularity of some words since specific authors may flood 300 the forums. Based on these considerations, the number of distinct first-authors was thus 301 chosen as the best indicator of popularity for active substances, brandnames and suppliers.

302 Nevertheless, it should be noted here that the question still remains whether the number of 303 distinct first authors may also be a relevant indicator of popularity of sellers or not. Indeed, 304 the presence of suppliers in discussions among different forums may be a better indicator of 305 popularity (see results). Thus, this indicator could avoid some flood effects due to the specific 306 activity of sellers. 
308 The temporal trends were evaluated using the date of the first post and the occurrences were

309 calculated using the number of distinct first author. The trends were reconstructed for the

310 groups of active substances, the brand names of products and the supplier's names. Only

311 words counted more than 25 times were selected. The trend analysis was thus performed on

312290 different terms, and 515 terms were discarded.

313 To classify the different patterns of popularity over time, an exploratory approach based on a 314 trajectory analysis was used. In a second phase, the trends were checked manually to 315 confirm their classification. Among the different techniques available, a group-based 316 approach applied in developmental social science has been chosen [19-22]. Indeed, it has 317 proven its applicability on criminological issues with the longitudinal analysis of crime rates 318 along street segments [23,24]. By analogy, it appears to be applicable to our specific context. 319 The group-based trajectory model proposed by Nagin allows the identification of clusters of 320 temporal trends sharing similar patterns of evolution in time. As the approach is parametric, 321 several options were tested to identify the best model. The type and the order of the 322 statistical model has been determined by testing all the available options; Zero Inflated 323 Poisson, Censored Normal, and Logit forms (for the type) and as linear, quadratic, and cubic 324 forms (for the order). The results show that a Censored Normal quadratic model suits best 325 our data. To determine the number of trajectory groups, all combinations of the numbers of 326 groups (starting from three) and polynomial order of each trajectory were tested. The 327 Bayesian Information Criterion (BIC) was used to estimate the optimal number of groups 328 (Equation 1). The number of groups is increased by one and the models are compared two329 by-two to see which one fits best. This procedure continues until the model became unstable. 330 The software STATA 13 and the special procedure "Proc Traj" were used to perform the 331 analysis [25].

$$
B I C=\log L-0.5 k \times \log N
$$

Equation 1: Bayesian Information Criterion (BIC). $L$ is the value of the model's maximized likelihood estimates, $\mathrm{N}$ is the sample size, and $\mathrm{k}$ is the number of parameters.

\section{Results and discussion}

340 Among all first authors, 43\% used at least once a word related to a doping product in their 341 topic titles. This suggests that the selected forums are highly specialized in doping matters. 342 The distribution of the different categories is quite similar in each forum. In other words, all 343 product categories are discussed similarly in each forum (see Table 4). There is no 344 specificity in spite of the different creation date of the forums and number of members. Thus, 
345 communities seem to be interested in the same general subjects. This observation is

346 supported by the comparison of the structure of the forums' sections.

347 Steroid is the main discussed category. More than $30 \%$ of first topics authors wrote at least

348 once about this category. This interest may be due to the long history of the usage of

349 steroids, the broad products offer and a deeper knowledge (e.g. effectiveness, side effects,

350 etc.). Peptide-growth factor-EPO, hormone-metabolic modulator and other anabolic agent

351 categories are respectively mentioned by 9,8 and $5 \%$ of topic authors. These four categories

352 include all the doping products known to enhance performance and image (PIED).

\begin{tabular}{|c|c|c|c|c|c|c|c|c|c|c|c|c|c|c|}
\hline Type of substances & 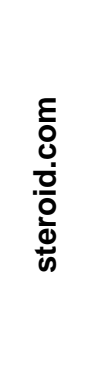 & 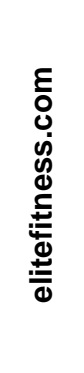 & 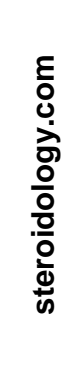 & 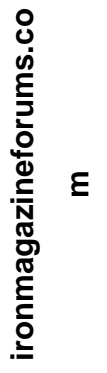 &  & 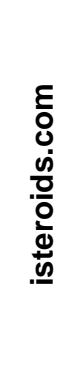 & 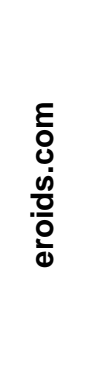 & 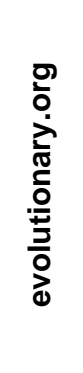 & 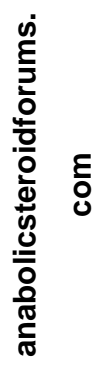 & 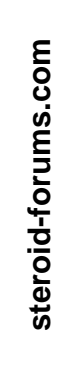 & 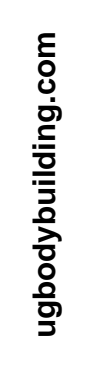 & 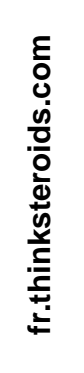 & 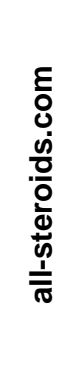 & $\begin{array}{l}\stackrel{0}{E} \\
\frac{5}{2} \\
\stackrel{2}{0} \\
\overline{\bar{\alpha}}\end{array}$ \\
\hline \multirow[t]{2}{*}{ Steroid } & 35.0 & 33.9 & 32.2 & 24.6 & 28.3 & 30.6 & 25.8 & 26.0 & 29.3 & 24.0 & 27.6 & 34.0 & 36.5 & 32.2 \\
\hline & 8 & 1 & 8 & 4 & 9 & 2 & 4 & 1 & 9 & 1 & 4 & 5 & 5 & 6 \\
\hline $\begin{array}{l}\text { Peptide, growth factor } \\
\text { and EPO }\end{array}$ & $\begin{array}{c}10.0 \\
2\end{array}$ & 8.44 & 8.61 & 7.93 & 9.54 & 8.26 & $\begin{array}{c}11.1 \\
3\end{array}$ & 7.39 & $\begin{array}{c}10.1 \\
2\end{array}$ & $\begin{array}{c}12.5 \\
1\end{array}$ & $\begin{array}{c}11.2 \\
0\end{array}$ & 8.71 & 8.45 & 9.21 \\
\hline Stimulant & 1.42 & 2.11 & 1.02 & 2.00 & 1.14 & 0.57 & 0.14 & 2.19 & 1.45 & 0.93 & 0.27 & 1.57 & 1.55 & 1.44 \\
\hline Beta-2-agonist & 0.35 & 0.39 & 0.27 & 0.17 & 0.38 & 0.59 & 0.05 & 0.69 & 0.23 & 0.16 & 0.36 & 0.59 & 1.03 & 0.34 \\
\hline Glucocorticoid & 0.18 & 0.19 & 0.12 & 0.20 & 0.21 & 0.10 & 0.15 & 0.11 & 0.16 & 0.08 & 0.09 & 0.00 & 0.17 & 0.17 \\
\hline $\begin{array}{l}\text { Diuretic and masking } \\
\text { agent }\end{array}$ & 0.12 & 0.29 & 0.12 & 0.01 & 0.18 & 0.10 & 0.06 & 0.08 & 0.10 & 0.00 & 0.00 & 0.10 & 0.00 & 0.15 \\
\hline Narcotic & 0.08 & 0.36 & 0.02 & 0.04 & 0.03 & 0.05 & 0.15 & 0.13 & 0.13 & 0.04 & 0.09 & 0.00 & 0.00 & 0.13 \\
\hline Cannabinoid & 0.01 & 0.02 & 0.01 & 0.01 & 0.00 & 0.00 & 0.00 & 0.00 & 0.00 & 0.00 & 0.00 & 0.00 & 0.00 & 0.01 \\
\hline All categories & 46 & 46 & 41 & 41 & 41 & 40 & 38 & 41 & 39 & 37 & 39 & 45 & 47 & 43 \\
\hline
\end{tabular}

354 Table 4 - Percentages of the number of distinct first authors talking about each category of

$355 \quad$ products. Categories are adapted from WADA prohibited list (2015). 
357 The top 10 active substances of each forum were similar. Therefore, the results are

358 presented and discussed for all forums (see table 5).

359

\begin{tabular}{|c|c|c|c|c|c|c|c|c|c|}
\hline \multirow{2}{*}{\multicolumn{2}{|c|}{$\begin{array}{l}\text { Steroids [\%] } \\
n=176146\end{array}$}} & \multirow{2}{*}{\multicolumn{2}{|c|}{$\begin{array}{l}\text { Peptides, Growth factor } \\
\text { and EPO [\%] } \\
n=176146\end{array}$}} & \multirow{2}{*}{\multicolumn{2}{|c|}{$\begin{array}{c}\text { Hormones and } \\
\text { metabolic modulators [\%] } \\
n=176146\end{array}$}} & \multirow{2}{*}{\multicolumn{2}{|c|}{$\begin{array}{c}\text { Others anabolic } \\
\text { agents [\%] } \\
n=176146\end{array}$}} & \multicolumn{2}{|c|}{ Stimulants [\%] } \\
\hline & & & & & & & & \multicolumn{2}{|c|}{$\mathrm{n}=176146$} \\
\hline testosterone & 15.68 & growth hormone & 4.90 & tamoxifen & 2.67 & clenbuterol & 4.18 & ephedrine & 1.13 \\
\hline methandrostenolone & 5.28 & gonadotropin & 3.43 & anastrozole & 2.32 & enobosarm & 0.28 & caffeine & 0.52 \\
\hline oxandrolone & 4.98 & igf & 1.62 & clomifene & 2.18 & ibutamoren & 0.07 & synephrine & 0.12 \\
\hline nandrolone & 4.81 & ghrp & 0.43 & insulin & 1.20 & lgd & 0.02 & phentermine & 0.07 \\
\hline trenbolone & 4.81 & melanotan & 0.19 & letrozole & 1.18 & & & methylphenidate & 0.03 \\
\hline stanozolol & 4.30 & CJC & 0.18 & exemestane & 0.66 & & & selegiline & 0.02 \\
\hline boldenone & 2.88 & thymosin & 0.14 & androstenetrione & 0.25 & & & $\begin{array}{c}\text { methylhexanami } \\
\text { ne }\end{array}$ & 0.02 \\
\hline oxymetholone & 1.63 & EPO & 0.11 & cardarine & 0.13 & & & kratom & 0.02 \\
\hline metenolone & 1.56 & mgf & 0.10 & arimistane & 0.12 & & & amphetamine & 0.01 \\
\hline drostanolone & 0.99 & ghrh & 0.05 & toremifene & 0.11 & & & modafinil & 0.01 \\
\hline $\begin{array}{c}\text { dehydrochlormethyl- } \\
\text { testosterone }\end{array}$ & 0.96 & pgf & 0.04 & raloxifene & 0.11 & & & sibutramine & 0.01 \\
\hline mesterolone & 0.60 & triptorelin & 0.03 & formestane & 0.06 & & & cocaine & 0.01 \\
\hline methasterone & 0.73 & gvs-111 & 0.01 & & & & & dopamine & 0.01 \\
\hline DHEA & 0.54 & & & & & & & & \\
\hline methyl-1-testosterone & 0.35 & & & & & & & & \\
\hline
\end{tabular}

360

\begin{tabular}{|c|c|c|c|c|c|c|c|}
\hline \multirow{2}{*}{\multicolumn{2}{|c|}{$\begin{array}{l}\text { Beta-2-agonists } \\
\qquad n=176146\end{array}$}} & \multicolumn{2}{|c|}{ Glucocorticoids } & \multicolumn{2}{|c|}{$\begin{array}{c}\text { Diuretics and } \\
\text { masking agents }\end{array}$} & \multicolumn{2}{|c|}{ Narcotics } \\
\hline & & \multicolumn{2}{|c|}{$n=176146$} & \multicolumn{2}{|c|}{$\mathrm{n}=176146$} & \multicolumn{2}{|c|}{$\mathrm{n}=176146$} \\
\hline \multirow[t]{3}{*}{ salbutamol } & 0.34 & corticosteroid & 0.13 & spironolactone & 0.08 & ghb & 0.12 \\
\hline & & prednisone & 0.03 & furosemide & 0.06 & heroin & 0.01 \\
\hline & & & & glycerol & 0.02 & & \\
\hline
\end{tabular}

361 Table 5 - Percentages of first authors talking about each substance by active substances, for each class of doping product.

364 Testosterone is the most represented substance among steroids. Only a few authors

365 described precisely the composition of a product, therefore, all esters were merged for one

366 substance. Testosterone is the endogenous anabolic steroid naturally present in the body.

367 Moreover, the main goal of taking an anabolic agent is to produce more testosterone or 368 mimic its body effect [26]. This may probably explain why this steroid is the most visible 369 substance in forums. It also surpassed all the other categories of active substances in terms 370 of the number of topics opened by authors. The other substances in the steroids class are 
371 well known synthetic anabolic steroids. They have been involved in a lot of doping cases and

372 known to be effective [27]. Therefore, this is not surprising that they are popular in online

373 discussions.

374 Concerning the growth factors, peptides and EPO category, growth hormone is the most 375 represented substance. In forums, this substance is discussed as an alternative of steroids to 376 enhance muscle mass [28]. It stimulates many metabolites process such as secretion of 377 Insulin-like Growth Factor-I (IGF-1) and plays a key role in muscle protein synthesis. Growth 378 factors seem more popular than peptides and EPO, which may be explained by their 379 longstanding use compared to peptides. In the case of EPO, only $0.11 \%$ of first topic authors 380 spoke about it. It is likely due to the fact that EPO is used as blood doping agents in 381 endurance sports and do not have an effect on muscle mass. Therefore, this substance is 382 not worthwhile for fitness practitioners.

383 The substances in the other categories are much less popular. Except for ephedrine which is 384 used to lose weight, there is a low interest in illegal drugs such as amphetamine, cocaine, 385 heroin and cannabis. This may be explained by the fact that those substances are less 386 related to the field of bodybuilding or authors are less willing to discuss them publicly.

387 Globally, the most discussed substances are also the most used in bodybuilding according to 388 the review proposed by Kam and Yarrow [29]. Steroid, other anabolic agents and growth 389 factors are consumed to enhance muscle mass while hormone and metabolic modulators to 390 avoid side effects due to previous substances [2].

392 Popularity of Brand names

393 To analyse the popularity of brand names, all products with a brand name similar to an active 394 substance were removed from the ranking analysis (see Table 6). It has to be noted that a 395 brand name is not necessarily related to only one producer. For example, Sustanon is a 396 trademark owned by Organon but other producers such as UKpharmalab has taken the 397 same brand name. 


\begin{tabular}{|c|c|c|c|c|c|c|c|c|}
\hline \multicolumn{3}{|c|}{$\begin{array}{l}\text { Steroids } \\
n=176146\end{array}$} & \multicolumn{3}{|c|}{$\begin{array}{l}\text { Peptides, GF and EPO } \\
\qquad n=176146\end{array}$} & \multicolumn{3}{|c|}{$\begin{array}{c}\text { Hormones and metabolic } \\
\text { modulators } \\
n=176146\end{array}$} \\
\hline Brandname & Active substance & [\%] & Brandname & $\begin{array}{l}\text { Active } \\
\text { substance }\end{array}$ & [\%] & Brandname & $\begin{array}{l}\text { Active } \\
\text { substance }\end{array}$ & {$[\%]$} \\
\hline anavar & oxandrolone & 4.40 & jintropin & hGH & 0.17 & nolvadex & tamoxifen & 2.40 \\
\hline $\begin{array}{l}\text { deca- } \\
\text { durabolin }\end{array}$ & nandrolone & 4.33 & tb-500 & peptide & 0.17 & clomid & clomiphene & 2.32 \\
\hline winstrol & stanozolol & 4.18 & ipomorelin & GHRP & 0.12 & arimidex & anastrozol & 1.25 \\
\hline danabol & methandrostenolone & 4.13 & somatropin & hGH & 0.07 & liquidex & anastrozol & 0.67 \\
\hline sustanon & testosterone & 3.50 & serostim & hGH & 0.10 & aromasine & exemestane & 0.66 \\
\hline equipoise & boldenone & 2.62 & pregnyl & gonadotropin & 0.05 & aromadex & exemestane & 0.30 \\
\hline primobolan & metenolone & 1.58 & semorelin & GHRH & 0.09 & tamox & tamoxifen & 0.13 \\
\hline anadrol & oxymetholone & 1.41 & genotropin & hGH & 0.11 & humalog & insulin & 0.08 \\
\hline masteron & drostanolone & 0.94 & nutropin & hGH & 0.03 & formeron & formestane & 0.03 \\
\hline proviron & mesterolone & 0.94 & saizen & hGH & 0.04 & teslac & testolactone & 0.02 \\
\hline turinabol & $\begin{array}{l}\text { dehydrochlormethyl- } \\
\text { testosterone }\end{array}$ & 0.25 & hexarelin & GHRP & 0.07 & evista & raloxifen & 0.01 \\
\hline anapolon & oxymetholone & 0.08 & kigtropin & hGH & 0.06 & liquinolva & tamoxifene & 0.01 \\
\hline \multirow[t]{2}{*}{ androtardyl } & testosterone & 0.01 & igtropin & IGF & 0.02 & liquifem & Letrozole & 0.01 \\
\hline & & & hygetropin & hGH & 0.35 & & & \\
\hline
\end{tabular}

Other anabolic agents

\begin{tabular}{ccc}
\multicolumn{3}{c}{$\mathrm{n}=176146$} \\
\hline Brandname & $\begin{array}{c}\text { Active } \\
\text { substance }\end{array}$ & {$[\%]$} \\
\hline osta rx & clenbuterol & 0.09 \\
liquiclen & clenbuterol & 0.04 \\
superclen & clenbuterol & 0.03 \\
spiropent & clenbuterol & 0.03 \\
oxyflux & clenbuterol & 0.02 \\
ventipulmin & clenbuterol & 0.02 \\
\hline
\end{tabular}

398

399 Table 6 - Percentages of the number of first authors talking about each brand names by 
401 In the steroid category, some brand names like Anavar, Sustanon, Winstrol, Deca-Durabolin

402 are originating from the pharmaceutical industry. Currently, pharmaceutical industries, 403 whether they are more or less legit depending of the country, also used those brand names 404 likely because of their quality reputation. For example, Deca-Durabolin is a brand name 405 owned by Aspen Global Incoporated (International registration: 693884A) which is used by 406 several suppliers, such as Organon, Teragon Labs, Meditech.

407 Brand names, such as Equipoise, come from the veterinary field (in higher doses than 408 pharmaceutical products) but they are used by humans. Globally, the brand names ranking 409 matches the previous ranking of active substances (see Table 5 and 6). Finally, forum 410 members refer more frequently to the brand name than directly to the active substance 411 name, in particular for stanozolol, methandrostenolone, nandrolone and oxandrolone.

412 Brand names of human growth hormone are the most represented among the group 413 "peptides, GF and EPO". Fewer differences are observed between the brand names of 414 human growth hormone. Therefore, consumers do not seem to have a particular preferred 415 product in this category.

416 Concerning brand names in the hormones and metabolic modulators category, the three 417 most popular are pharmaceuticals. This result supports the hypothesis that consumers like 418 (at least discuss) more pharmaceutical products than non-official products. This may be due 419 to their effectiveness and quality reputation.

\section{Popularity of Suppliers}

422 Unlike the brand names ranking or the active substances ranking, the suppliers' ranking is 423 specific to each forum. This is likely due to the presence of affiliate suppliers with specific 424 sections, advertising banner and/or selling part of the same website.

425 Table 7 shows the ranking of the 20 most discussed suppliers according to the number of 426 first topic authors. The numbers of first authors discussing suppliers increases exponentially 427 with the number of their apparition in distinct forums ([number of authors] = $4284.1743 \mathrm{e}^{0.3402[\text { number of forums] }}, \mathrm{R}^{2}=0.936$, see Figure 4). Therefore, the presence of a supplier in 429 discussions among different forums seems to be a better indicator of popularity. As 430 previously stated, this indicator could avoid some flood effects due to the specific activity of 431 sellers. For example, RUI-products are discussed by more than 800 authors in only one 432 forum (accounting for $70 \%$ of all authors talking about these substances). These authors are 433 likely linked because they post exactly the same advertising thread. The observation time of 434 suppliers is defined as the time interval between the first thread and the last one where they 435 appear. The mean observation time is 5 years with a median of 4 years (see Figure 5 ). This 436 is a first indication about the life time of suppliers. However, it's not possible to verify if a 
437 supplier brand name is used by several groups of suppliers. Additionally, consumers can 438 discuss a supplier even after it stops its activity.

439

\begin{tabular}{lccc}
\hline Supplier & Authors & Forums & Observation time [years] \\
\hline RUI-Products (AR-R) & 1131 & 10 & 11 \\
Ttokkyo Laboratories & 733 & 7 & 11 \\
British Dragon & 602 & 13 & 14 \\
Denkall & 420 & 7 & 14 \\
Generic Labs & 405 & 11 & 14 \\
Organon & 389 & 12 & 14 \\
Norma Hellas & 333 & 11 & 12 \\
Black Cat Lab & 286 & 12 & 14 \\
Sciroxx Laboratories & 230 & 12 & 7 \\
Geneza Pharmaceuticals & 195 & 12 & 7 \\
Axiolabs & 189 & 11 & 8 \\
AG-Guys & 184 & 9 & 11 \\
Desma Zambon & 181 & 7 & 12 \\
Galenika & 177 & 10 & 13 \\
Orbit Nutrition & 168 & 8 & 12 \\
Balkan Pharmaceutical & 162 & 13 & 8 \\
Euroking gear & 161 & 10 & 5 \\
Syd Group & 159 & 9 & 12 \\
Pinnacle Labs & 158 & 9 & 13 \\
Hardcorelabs & 152 & 10 & 14 \\
\hline
\end{tabular}

441 Table 7- Ranking of the top 20 suppliers according to the number of first authors, their presence on forums and the observation time. 


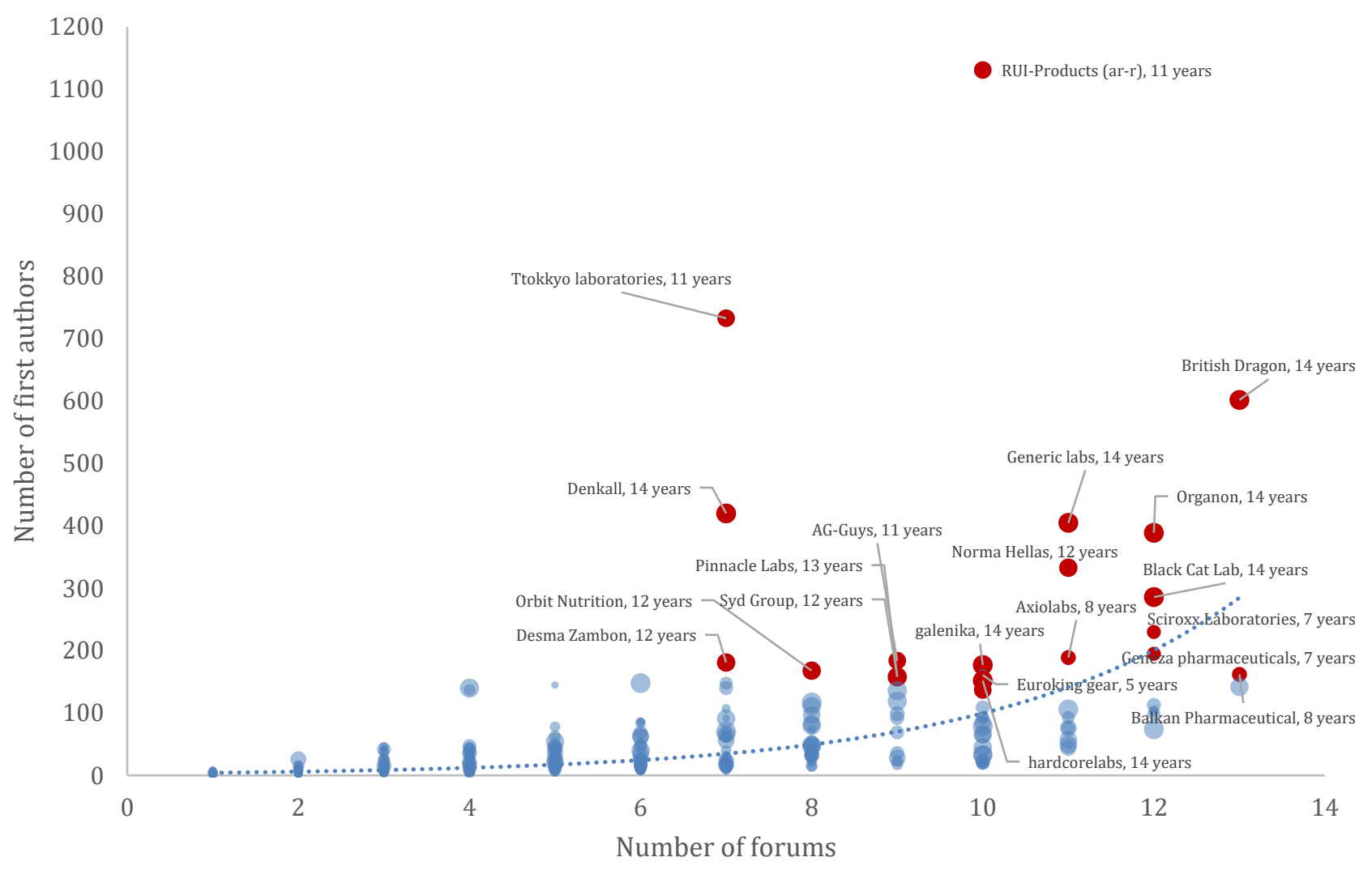

Number of forums

444 Figure 4 - Popularity of the 327 suppliers according to their presence on forums and the number of first authors who discussed them. In red: the top 20 suppliers according to the numbers of first authors (see Table 7). The circle size is proportional to the observation time

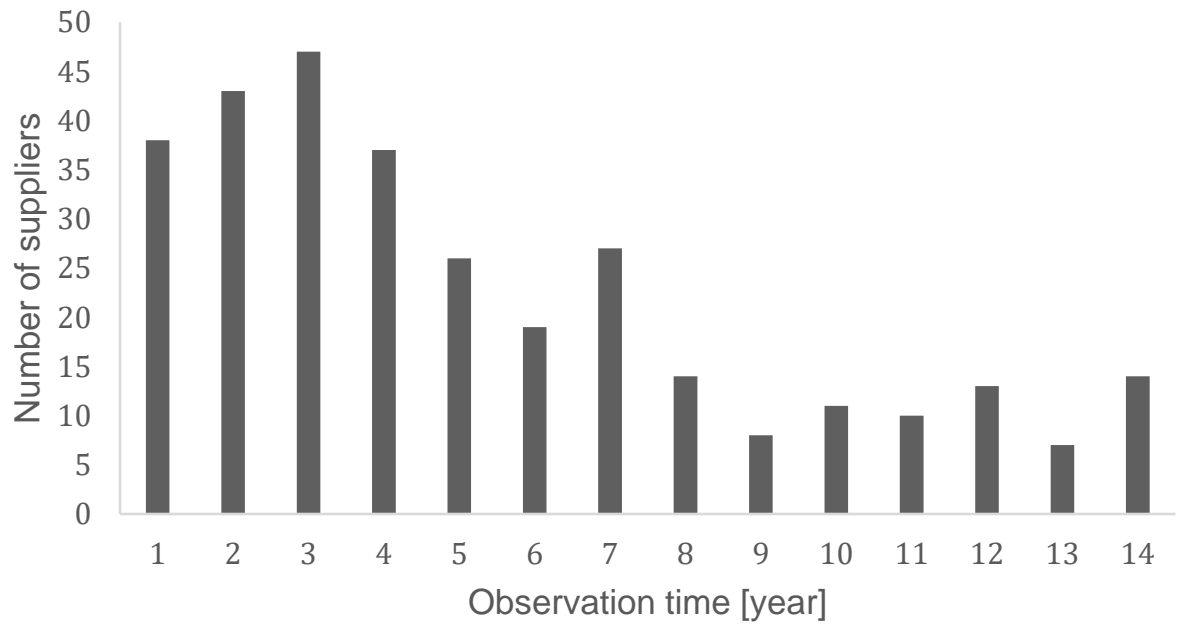

Figure 5 - Observation time of suppliers $(n=327)$ 
Means of contact used by sellers

455 Besides banners, three kinds of advertising strategies were detected in topic titles. The main 456 strategy is to promote a selling website ( $n=260$ suppliers). The second one is to give an e457 mail address to contact the supplier ( $n=47$ suppliers). Among the detected e-mails, the 458 suppliers commonly used a provider selling a secured and anonymous service (Table 8). 459 Finally, the last strategy is to contact the supplier through the private message system of the 460 forum. Measuring this third strategy is difficult because any user can be contacted by a 461 private message. The contact information was not detected for 80 suppliers because they 462 seem to have disappeared.

463

464

\begin{tabular}{cc}
\hline hostname & $\mathbf{n}$ \\
\hline securenym.net & 14 \\
safe-mail-net & 12 \\
countermail.com & 5 \\
neomailbox.ch & 2 \\
others & 14
\end{tabular}

465

\section{Trends analysis}

467 Global trends

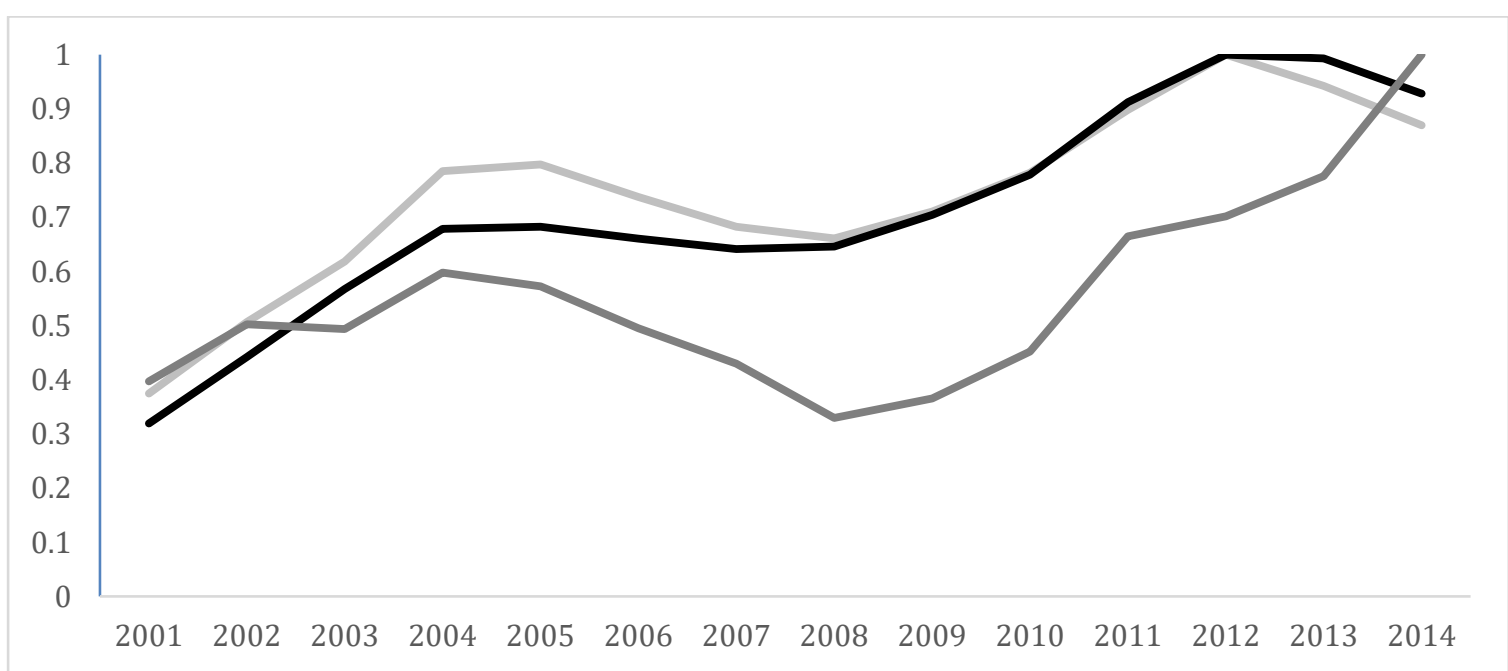

Figure 6: Temporal evolution of the number of first authors of topics. In black: the global/whole/full dataset $(n=176621)$, in middle grey: the supplier discussions $(n=13500)$,

473 The Figure 6 presents the general posting trend on the 13 forums. The number of 474 discussions about doping product topics is rising for the last 15 years according to the 475 general trend. After the launch period of the three biggest forums (Table 1), the expansion of 
476 active authors slowed down between 2005 and 2010. The same trend is observed for the 477 suppliers with a stronger decrease.

478 Several assumptions could explain this pattern. In 2005 and 2007, two operations were 479 conducted by the US Drug Enforcement Administration (DEA): "Operation Raw Deal" [30] 480 and "Operation Gear Grinder" [31]. As a result, 56 steroid laboratories and 8 companies were 481 identified and their products seized. These events could explain a diminution of the visibility 482 of suppliers. Indeed, some members included the suppliers could be more careful, to avoid 483 being targeted. On the other hand, the appearance and increasing importance of social 484 networking services (e.g. Facebook in 2004) could bring a displacement of the forums 485 members to a new trendy way of communication.

486

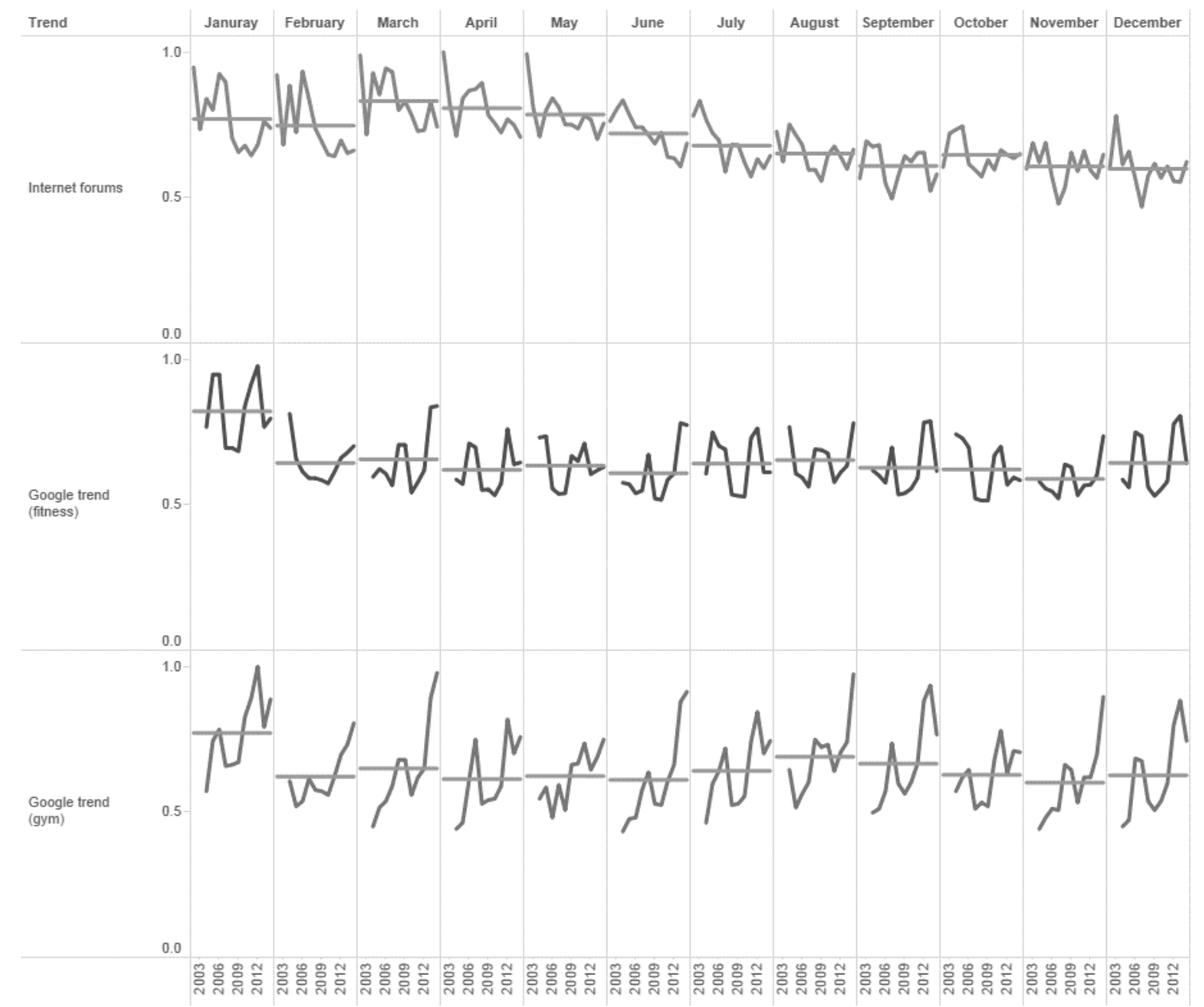

490 The seasonality is presented in Figure 7. The number of topics is bigger at the beginning of 491 the year (January to May). This seasonal trend may be due to some "good New Year's 
492 resolutions". This trend is confirmed by data collected through Google trends ${ }^{2}$ that shows the 493 same cyclicality for January (with 'gym' and 'fitness' as keywords). The seasonal trend 494 makes us assume that the main interest of the forum's members is the use of doping agents 495 in a fitness context. Indeed, Read [32] concluded that $75 \%$ of all gym memberships are taken 496 out in January.

Categories of doping products

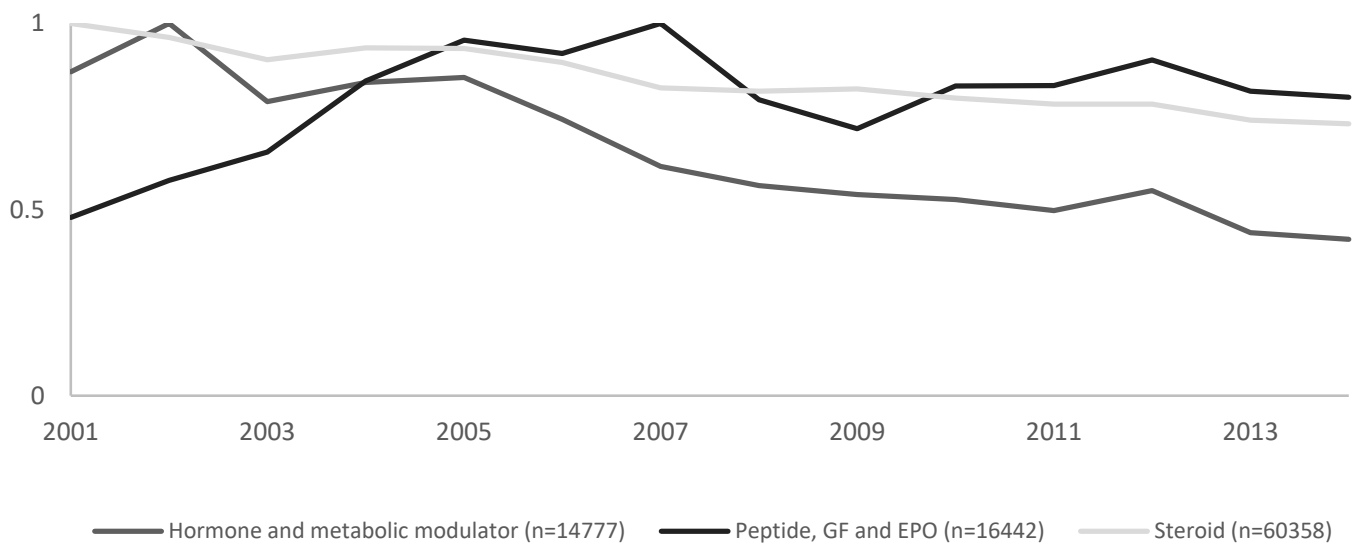

Figure 8: General trends for the 3 most popular categories.

502 Among categories, the hormones and metabolic modulators category has a downward trend

503 from 2002 to 2014 (see Figure 8). The steroids category has a chronic trend (always high)

504 slightly decreasing. This can be due to a saturation effect. Indeed, the number of discussions 505 could decline because of the large number of topics already posted which may answer the 506 majority of the members' enquiries. Additionally, a displacement of the use of a specific type 507 of products could also partially explain these trends.

508 Discussions about peptides and growth factors increase since 2001 with a maximum in 2007.

509 Compared to other categories of substances, they are the new generation of doping agents 510 [33]. Members of forums seem to speak a lot about them and continuously open new topics 511 to answer their questions. In addition, these substances have a reputation, inside the forums 512 community, to be medically safer with none or fewer side effects than anabolic steroids. 


\section{Products, brand names and suppliers}

514 The trend analysis was performed on 290 different terms, 515 terms being discarded, due to

515 their low occurrences $(n<25)$. The number of active substances, brand names and suppliers

516 analysed can be found in table 9.

517 The group-based trajectory analysis classified trends in 4 groups: upward trends, chronic

518 trends, downward trends and temporary increase. In a second phase, these groups were

519 checked manually to confirm their classification. The automated method correctly classified

520 them depending on the type of trend: chronic trends at $34 \%$, upward trends at $75 \%$;

521 downward trends at $76 \%$ and temporary increases at $65 \%$. Chronic trends are misclassified

522 due to the overlaps with the temporary increase type. This automated method saved time

523 and helped to define the main groups of the trends. However, results show that a manual

524 verification is still necessary to ensure a reliable classification. The results are summarized in

525 Table 9.

526

\begin{tabular}{cccccc}
\hline & Chronic & Upward & Downward & Temporary increase & $\boldsymbol{n}$ \\
\hline Substances & $14 \%$ & $20 \%$ & $32 \%$ & $34 \%$ & 97 \\
Brandnames & $8 \%$ & $8 \%$ & $48 \%$ & $36 \%$ & 132 \\
Suppliers & $2 \%$ & $54 \%$ & $18 \%$ & $26 \%$ & 61
\end{tabular}

529 A sample of trends of active substances, brand names and suppliers in each of the four 530 trends categories are respectively shown in Figures 9 to 11.

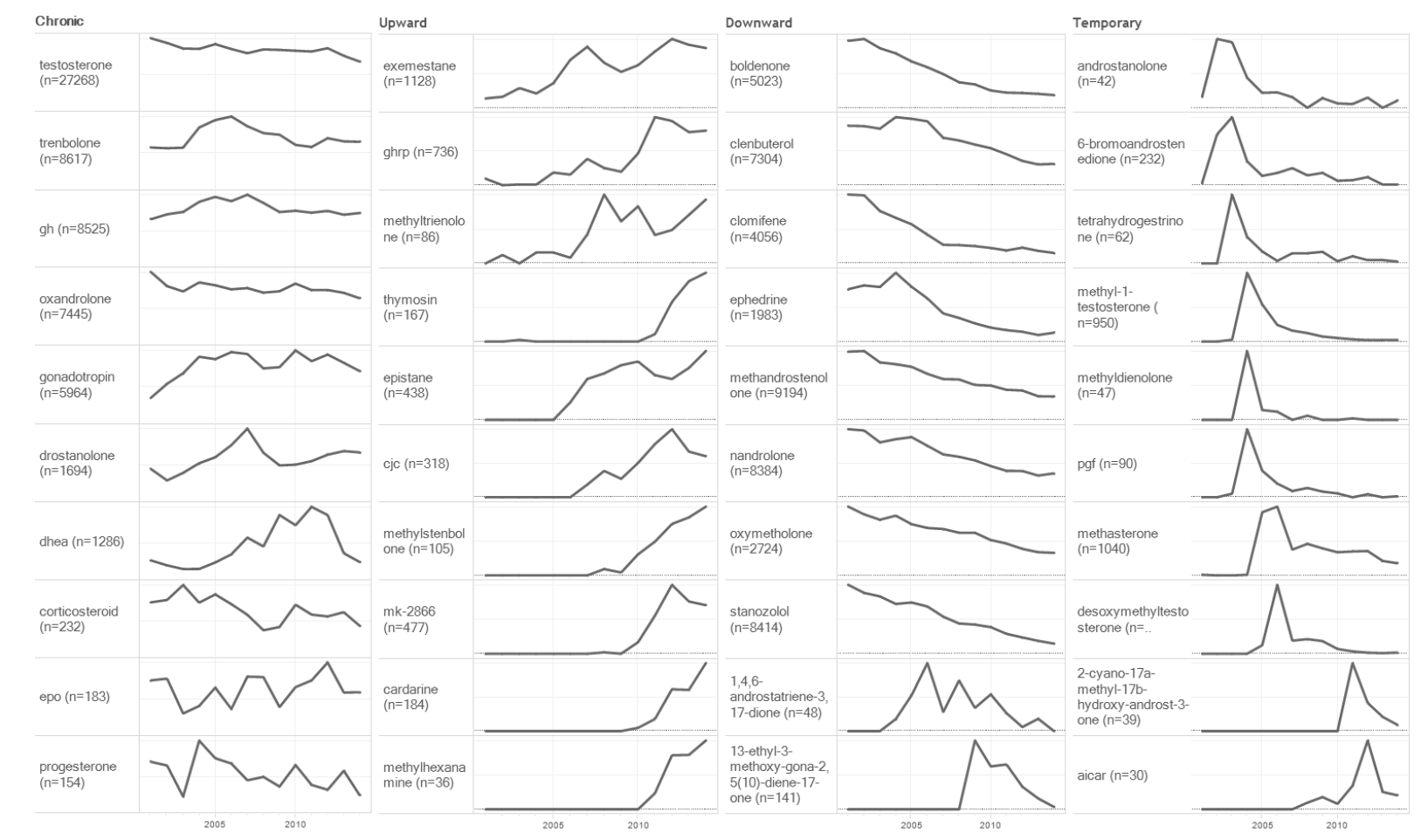

Figure 9: Sample of 40 trends for active substances $(n=97)$. 


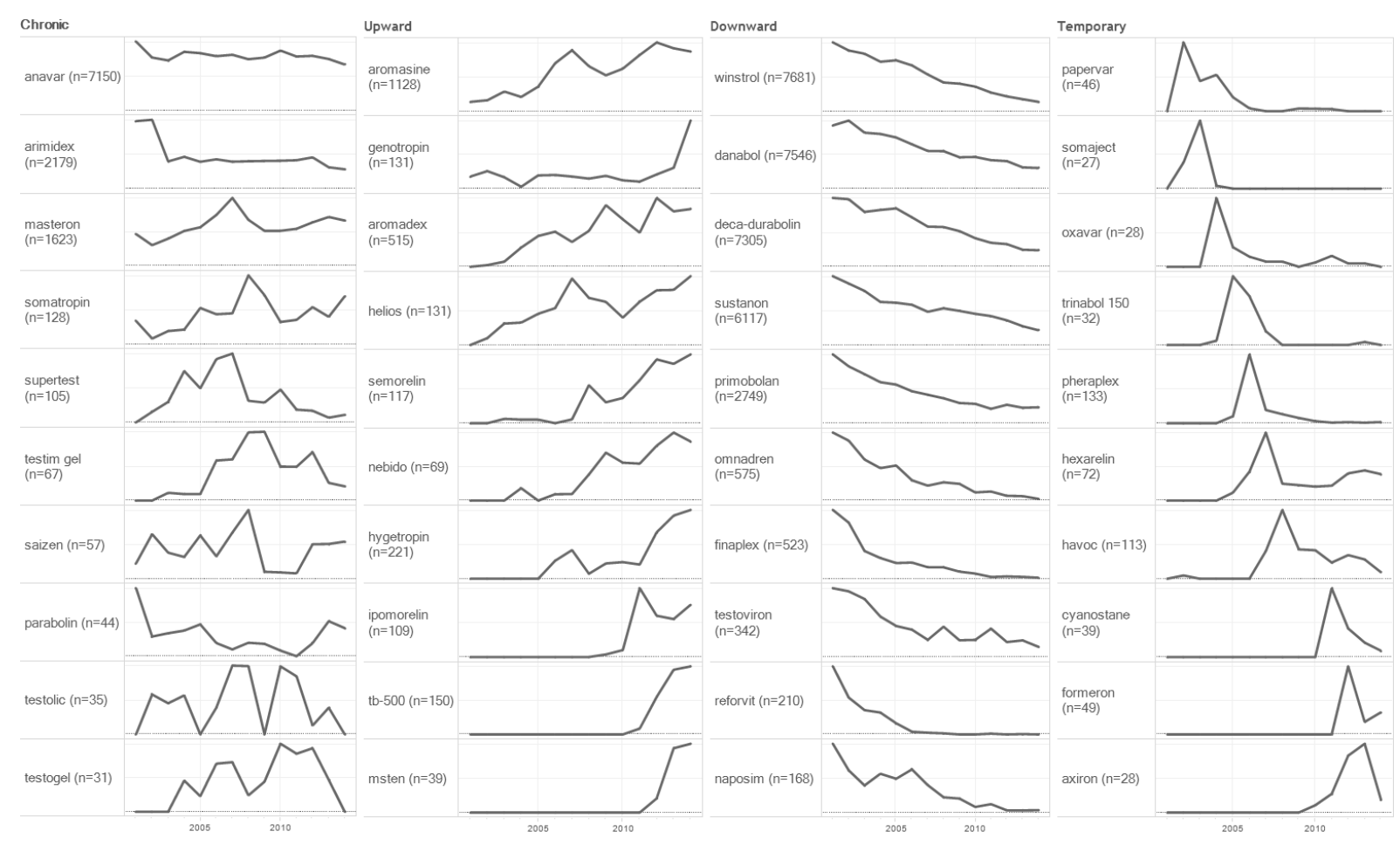

Figure 10: Sample of 40 trends for brand names $(n=132)$.
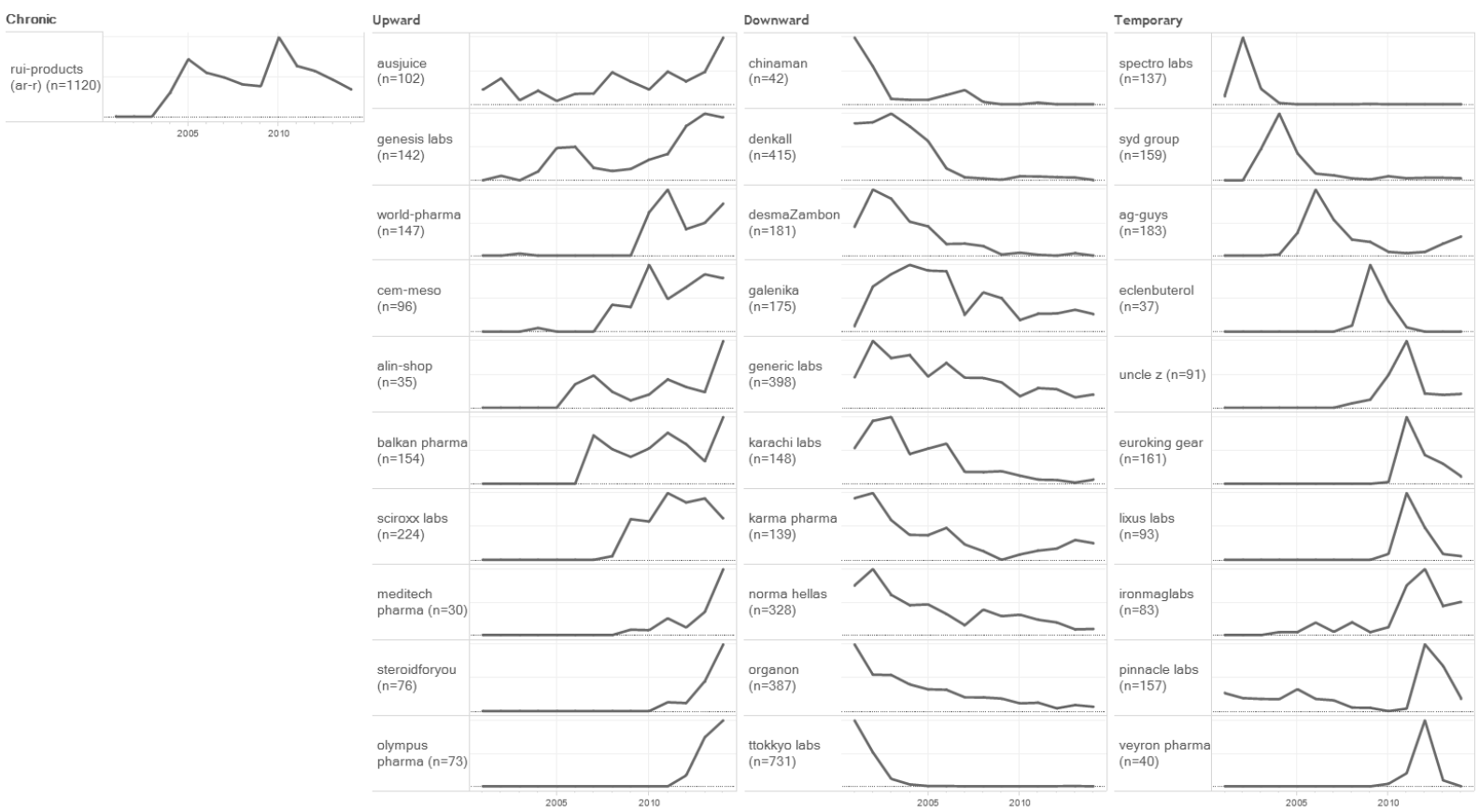

Figure 11: Sample of 31 trends for suppliers $(n=61)$.

540 Several assumptions can be drawn up about the trends. Upward trends could be due to the

541 growing popularity of a product or a supplier as a result of customer satisfaction, new entry

542 on the market or in the prohibited list edited by the WADA. For example, Ostarine (mk-2866)

543 is a selective androgen receptor modulator (SARM) which was banned by WADA in 2008. 
544 The Swiss laboratory for Doping Analyses reported the first case of abuse involving SARMs

545 in 2010 [34]. This product showed an upward trend since 2010 (year of its first detection in

546 community forums, see Figure 9). It is worth noting that only few brand names, substances

547 or suppliers showed an upward trend (63 on 290).

548 Chronic trends could be due to the quality and the reliability of products and suppliers 549 respectively. Additionally, the promotional strategies of suppliers could also impact the trend 550 as shown below. The majority of the chronic trends is stable since 2001 . This stability 551 suggests that products or suppliers are well established in the market and therefore have a 552 strong reputation or an intense promotional strategy. For example, testosterone is the leader 553 anabolic steroid on the market and has a chronic trend since 2001. RUI-product also known 554 as AR-R is the only supplier showing a chronic trend since 2004. The promotion of this 555 supplier in the community forums was very extensive with many different usernames.

556 Downward trends could be due to customers' dissatisfaction, saturation effect, market 557 competition, less accessibility or diversity of supply. For example, the majority of the most 558 popular substances or brand names such as danabol, deca-durabolin, clenbuterol, clomifene 559 and pgf showed downward trends likely due to a saturation effect. As previously explained, 560 large number of topics are already in place answering members' enquiries.

561 Finally, temporary increases could be due to media effect, sudden disappearance such as a 562 laboratory shutdown or advertising campaign. For example, tetrahydrogestrinone (THG) is an 563 anabolic steroid with a maximal popularity in 2003. In this year, it was firstly detected when a 564 syringe containing the drug was given to the U.S. Anti-Doping Agency (USADA) [35]. 565 Consequently, a number of athletes were tested positive for THG. The THG scandal and the 566 increase in popularity are concomitant. Another example is eclenbuterol which was a supplier 567 selling through the website "www.eclenbuterol.com". Its website was opened in 2008 and 568 shutdown the last semester of 2009 according to the forums posts and www.archive.org (last 569 access: May 2016). The temporary trend corresponded to the short observation time of this 570 supplier with a majority of topics concerning its disappearance.

571 Substances are mainly classified in downward or temporary increased categories. The 572 substances with an occurrence (n) higher than 2000 are chronic or slightly downward. Brand 573 names are much related to the substances. Therefore, they present the same pattern of 574 trends. However, suppliers are mostly classified in the upward category with a start after 5752011 and the temporary increases last a maximum of three years. Additionally, only one 576 supplier was chronic. Therefore, suppliers seem to have a short lifetime probably due to the 577 low stability of the market. 


\section{Conclusion and perspectives}

580 The study focuses on the detection of doping substances and suppliers discussed in Internet

581 forums to acquire a comprehensive understanding of the online market. 13 community 582 forums on the Internet were investigated and nearly one million topics were extracted with 583 source code scrappers.

584 The results show that the most discussed type of products is anabolic androgenic steroids 585 which is used to enhance body image and performance. The most popular products are 586 stable over time, and the emergence of new products such as peptides is observed. 327 587 suppliers were detected with mostly dedicated websites or direct sales by e-mail as selling 588 methods. Globally, the proposed methodology shows its ability to detect products and 589 suppliers and follow their temporal trends.

590 The generated intelligence will serve to guide the searching process, presented as 591 intelligence-led screening, of the online doping marketplaces based on the most popular 592 terms (i.e. keywords) used for both active substances and brand names. Additionally, it 593 allows the enhancement of customs inspection strategies and anti-doping analysis by 594 monitoring the most discussed and emerging substances. For example, a list of emerging 595 substances or the reference file (containing information such as the names of active 596 substances, brands or suppliers) may be provided to actors involved in anti-doping regulation 597 to improve their knowledge. Additionally, trends can be monitored in real time and accessible 598 through a community platform or a dashboard. These trends can be used to assess 599 operational decision or prevention on a specific substance, category or supplier.

600 As limitations, this study focused only on indexed forums on the surface web. Darknet and 601 deep web forums could be investigated to obtain a better overview. Moreover, discussions in 602 topics have not been taken into account. Thus, some words related to doping matter may be 603 missed. Compounds terms also were not detected, except for some names of laboratories 604 (e.g. British Dragon). Additionally, the popularity is only based on the number of first-topic 605 authors using the words. Therefore, positive or negative opinions were not taken into 606 account. Sentiment analysis could be performed in a second step to obtain a more precise 607 assessment about the popularity of products and sellers. Moreover, a study of other medium 608 of communication (such as social networking services) could bring additional and 609 complementary information about the popularity and sales of doping products.

610 As perspectives, trends comparison with customs and law enforcement seizures as well as 611 WADA-accredited laboratories results is currently ongoing to obtain a cross-validation of the 612 popularity of doping products. The comparison also aims at evaluating the hypothesis that 613 the most discussed products are the most consumed. Additionally, since May 2015, the most 614 popular terms identified in this study that are related to steroids are currently used in a 
615 systematic monitoring process on search engines and social networking services to detect 616 websites selling doping products.

617 Finally, it is assumed that the described methodology can be widely applied to other types of 618 crime problems and security issues. For example, the monitoring of extremist groups in 619 forums, market analysis, and other research purposes in forum communities. 


\section{Bibliography}

621 [1] A. Donati, World traffic in doping substances, 2007.

622 [2] F. Sjöqvist, M. Garle, A. Rane, Use of doping agents, particularly anabolic steroids , 623 in sport and society, Lancet. 371 (2008) 1872-1882.

624 [3] B.J. Jansen, A. Spink, How are we searching the World Wide Web? A comparison of 625

[4] R. Koopmans, A. Zimmermann, Visibility and communication networks on the internet: The role of search engines and hyperlinks, in: A Eur. Public Sph. How Much It Do We Have How Much Do We Need?, MZES, 2007: pp. 213-264.

[5] O. Ribaux, A. Baylon, C. Roux, O. Delémont, E. Lock, C. Zingg, P. Margot, Intelligence-led crime scene processing. Part I: Forensic intelligence., Forensic Sci. Int. 195 (2010) 10-6. doi:10.1016/j.forsciint.2009.10.027. Intelligence-led crime scene processing. Part II: Intelligence and crime scene examination., Forensic Sci. Int. 199 (2010) 63-71. doi:10.1016/j.forsciint.2010.03.011.

O. Ribaux, Police scientifique - Le renseignement par la trace, PPUR presses polytechniques, 2014.

O. Krug, A. Thomas, K. Walpurgis, T. Piper, G. Sigmund, W. Schänzer, T. Laussmann, M. Thevis, Identification of black market products and potential doping agents in Germany 2010-2013., Eur. J. Clin. Pharmacol. 70 (2014) 1303-11.

[10] F.G. Cordaro, S. Lombardo, M. Cosentino, Selling androgenic anabolic steroids by the doi:10.1007/s00228-014-1743-5.

647 [11] C.L. Clement, D.B. Marlowe, N.S. Patapis, D.S. Festinger, R.F. Forman, Nonprescription steroids on the Internet., Subst. Use Misuse. 47 (2012) 329-41. doi:10.3109/10826084.2011.630225.

[12] B.P. Brennan, G. Kanayama, H.G. Pope, Performance-enhancing drugs on the web: a growing public-health issue., Am. J. Addict. 22 (2013) 158-61. doi:10.1111/j.1521- 
[13] P.B. Kraska, C.R. Bussard, J.J. Brent, Trafficking in Bodily Perfection: Examining the Late-Modern Steroid Marketplace and Its Criminalization, Justice Q. 27 (2010) 159185. doi:10.1080/07418820902814013.

[14] J.-H. Wang, T. Fu, H.-M. Lin, H. Chen, Exploring Gray Web Forums: Analysis and Investigation of Forum-Based Communities in Taiwan, in: Stud. Comput. Intell. Vol. 135, Springer Berlin Heidelberg, Berlin, Heidelberg, 2008: pp. 121-134. doi:10.1007/978-3-540-69209-6_7.

[15] C. Seale, J. Charteris-Black, A. MacFarlane, A. McPherson, Interviews and internet forums: a comparison of two sources of qualitative data., Qual. Health Res. 20 (2010) 595-606. doi:10.1177/1049732309354094.

[16] M.J. Barratt, Discussing illicit drugs in public internet forums : Visibility , stigma , and pseudonymity, C T. (2011) 159-168. doi:10.1145/2103354.2103376.

[17] Y. Zhou, J. Qin, G. Lai, H. Chen, Collection of U . S . Extremist Online Forums : A Web Mining Approach Department of Systems and Industrial Engineering, University of Arizona Department of Management Information Systems , University of Arizona, (2007) 1-10.

[18] Z. Yao, C. Ze-Wen, Research on the construction and filter method of stop-word list in text preprocessing, Proc. - 4th Int. Conf. Intell. Comput. Technol. Autom. ICICTA 2011.1 (2011) 217-221. doi:10.1109/ICICTA.2011.64.

[19] D. Nagin, K. Land, Age, criminal careers, and population heterogeneity: Specification and estimation of a nonparametric, mixed Poisson model, Criminology. 31 (1993) 327-362. doi:10.1111/j.1745-9125.1993.tb01133.x.

[20] D.S. Nagin, D.P. Farrington, T.E. Moffitt, Life-Course Trajectories of Different Types of Offenders, Criminology. 33 (1995) 111-139. doi:10.1111/j.1745-9125.1995.tb01173.x.

[21] D.S. Nagin, Analyzing developmental trajectories. A semi-parametric group based approach, Psychol. Methods. 6 (1999) 18-34. doi:10.1037/1082-989X.4.2.139.

[22] D.S. Nagin, Groupe-Based Modeling of Developpment, Harvard University Press, 2005.

[23] D. Weisburd, S. Bushway, C. Lum, S.-M. Yang, Trajectories of Crime at Places: A Longitudinal Study of Street Segments in the City Of Seattle, Criminology. 42 (2004) 283-321. doi:10.1111/j.1745-9125.2004.tb00521.x.

[24] D. Weisburd, E.R. Groff, S.-M. Yang, The criminology of place, Oxford university press, 2012.

[25] B.L. Jones, D.S. Nagin, K. Roeder, A SAS Procedure Based on Mixture Models for 
Estimating Developmental Trajectories, Sociol. Methods Res. 29 (2001) 374-393. doi:10.1177/0049124101029003005.

[26] T.D. Fahey, Anabolic-Androgenic Steroids: Mechanism of Action and Effects on Performance, Encycl. Sport. Med. Sci. (1998). http://www.sportsci.org/encyc/anabster/anabster.html (accessed July 27, 2016).

[27] R. Kazlauskas, Designer Steroids, in: Doping Sport., First Edit, Springer, 2010: pp.

[28] M. Saugy, N. Robinson, C. Saudan, N. Baume, L. Avois, P. Mangin, Human growth hormone doping in sport., Br. J. Sports Med. 40 (2006) 35-39. doi:10.1136/bjsm.2006.027573.

[29] P.C. Kam, M. Yarrow, Anabolic steroid abuse: Physiological and anaesthetic considerations, Anaesthesia. 60 (2005) 685-692. doi:10.1111/j.13652044.2005.04218.x.

[30] Department of Justice, International Law Enforcement Operation Targets

702

703

704

[31] Drug Enforcement Administration, DEA Leads Largest Steroid Bust in History, (2005).

705 https://www.dea.gov/pubs/pressrel/pr121505.html (accessed July 27, 2016).

[32] T. Read, D. Davies, The Secret Life of Money: Everyday Economics Explained, First Edit, London, 2015.

709

[33] Australian Crime Commission, Organised Crime and Drugs in Sport, 2013.

710

[34] E. Grata, L. Perrenoud, M. Saugy, N. Baume, SARM-S4 and metabolites detection in sports drug testing: A case report, Forensic Sci. Int. 213 (2011) 104-108.

712 [35] L.D. Bowers, Anti-dope testing in sport: The history and the science, FASEB J. 26 (2012) 3933-3936. doi:10.1096/fj.12-1001ufm. 